\title{
Association between genetic polymorphisms in AURKA (rs2273535 and rs1047972) and breast cancer risk: a meta-analysis involving 37,221 subjects
}

Zhi-Jun Dai ${ }^{1,2^{*}}$, Hua-Feng Kang ${ }^{1+}$, Xi-Jing Wang ${ }^{1+}$, Yong-Ping Shao ${ }^{2}$, Shuai Lin ${ }^{1}$, Yang Zhao ${ }^{1}$, Hong-Tao Ren ${ }^{1}$, Wei-Li Min ${ }^{1}$, Meng Wang ${ }^{1}$ and Xiao-Xu Liư ${ }^{{ }^{*}}$

\begin{abstract}
Background: Published data on the association between AURKA polymorphisms and breast cancer (BC) risk are inconclusive. This meta-analysis was performed to derive a more precise estimation on the relationship between AURKA polymorphisms (rs2273535 and rs1047972) and BC risk.

Methods: PubMed, Web of Knowledge and Embase were searched for relevant studies. Odds ratios (ORs) with 95\% confidence intervals (Cls) were used to estimate the strength of associations. The pooled odds ratios (ORs) with 95\% confidence intervals (Cls) were performed for allele contrast genetic model, homozygous genetic model, heterozygote genetic model, dominant model, and recessive model, respectively.

Results: A total of 13 studies (16,349 BC patients and 20,872 case-free controls) were involved in this meta-analysis. Meta-analysis showed that there was significant association between rs2273535 and BC risk in three genetic models in the overall population (A vs. T: $\mathrm{OR}=1.08,95 \% \mathrm{Cl}=1.01-1.15, P=0.02$; $\mathrm{AA}$ vs. T: $\mathrm{OR}=1.36,95 \% \mathrm{Cl}=1.06-1.73$, $P<0.00001$; AA vs. $T+\mathrm{TA}: \mathrm{OR}=1.15,95 \% \mathrm{Cl}=1.01-1.31, P=0.04)$. In the subgroup analysis by ethnicity, the effects remained in Asians (allele contrast genetic model: $\mathrm{OR}=1.12,95 \% \mathrm{Cl}=1.00-1.26, P=0.04$ and homozygote comparison: $\mathrm{OR}=1.22,95 \% \mathrm{Cl}=1.06-1.41, P=0.007)$. However, no genetic models reached statistical association in Cauasians. Rs 1047972 polymorphism was associated with BC risk in the overall population based on homozygote comparison (AA vs. GG: $\mathrm{OR}=0.81,95 \% \mathrm{Cl}=0.66-0.99, P=0.04$ ). When stratified by ethnicity, rs 1047972 polymorphism had a decreased association with BC risk in Caucasians based on allele contrast genetic model, homozygote comparison, the dominant model and the recessive model. However, there was no association in any genetic model in Asians.

Conclusions: This meta-analysis suggests that AURKA rs2273535 polymorphism has an increased risk with BC, especially in Asians. However, rs 1047972 polymorphism has a decreased BC risk in Caucasians. Further large scale multicenter epidemiological studies are warranted to confirm this finding.
\end{abstract}

Keywords: AURKA, Breast cancer, Polymorphism, Susceptibility, Meta-analysis

\footnotetext{
*Correspondence: dzj0911@126.com; xiaoxuliu0304@sina.com

'Equal contributors

'Department of Oncology, the Second Affiliated Hospital of Xi'an Jiaotong

University, Xi'an 710004, China

Full list of author information is available at the end of the article
} 


\section{Introduction}

Breast cancer (BC) is the most common cancer in women and the incidence has increased in recent years worldwide [1]. BC is also a complex disease with multiple epidemiological, genetic, and epigenetic factors contributing to disease etiology [2,3]. About $10 \%$ of all breast cancers are associated with family history [4]. The clinical features of human $\mathrm{BC}$ are characterized by a considerable heterogeneity.

AURKA, also known as STK15/Aurora-A, belongs to the Aurora family of cell cycle-regulating serine/threonine kinase [5]. AURKA is localized at the centrosome from the time of centrosome duplication to mitotic exit and regulates centrosome function [6]. AURKA plays an important role in mitotic centrosome separation, maturation and spindle formation and stability [5-7]. Studies have demonstrated that AURKA overexpression contributes to genetic instability and tumourigenesis by disrupting the proper assembly of the mitotic checkpoint complex and occurs in a high proportion of ovarian, bladder, gastric and breast cancers [8-11].

Two nonsynonymous polymorphisms F31I (rs2273535) and V57I (rs1047972) have been identified in the AURKA gene. Both polymorphisms are located within two conserved motifs in the N-terminal region of the AURKA gene [12]. Several studies have reported the role of AURKA polymorphisms in BC risk [13-25], but the results are inconclusive. For example, Ruan et al. [13] reported that the AA (Ile/Ile) genotype of rs2273535 was associated with a significantly increased risk of breast cancer among the Chinese Han population. However, Dai et al. Dai et al. [23] that rs2273535 allele of the AURKA gene was not associated with breast cancer risk (OR 1.2, 95\% CI 0.9-1.6). There was also no apparent difference in allele frequency or genotype of rs1047972 polymorphism (OR 0.8, 95\% CI 0.4-1.6) [23]. Fletcher et al. [20] demonstrated that the Ile/Ile homozygous genotype was not associated with an increased $\mathrm{BC}$ risk in white women of British descent. Egan et al. described an increased risk associated with a compound genotype of the two polymorphisms, rs2273535 and rs1047972, with individuals homozygous for the 31I and $57 \mathrm{~V}$ alleles having a nearly 2-fold increase in risk of postmenopausal invasive BC [24].

Therefore, we carried out this meta-analysis on all eligible case-control studies to derive a more precise estimation of the associations between AURKA polymorphisms (rs2273535 and rs1047972) with BC risk.

\section{Materials and methods Publication search}

We searched the articles in PubMed, Web of Knowledge and Embase to collect articles with case-control studies related to the association of AURKA polymorphisms and $\mathrm{BC}$ risk. The keywords were as follows: breast cancer/ breast carcinoma, AURKA/Aurora-A/STK15, polymorphism/genotype/SNP. All qualified studies were searched until May 30, 2014. The eligible articles must be published in English. Furthermore, reference lists of main reports and review articles were also reviewed by a manual search to identify additional relevant publications.

\section{Selection and exclusion criteria}

The following criteria were used to select studies for further meta-analysis: (1) case-control studies; (2) the studies evaluated the associations between AURKA polymorphisms and breast cancer risk; (3) all cases were diagnosed by pathological examination; (4) the studies contained sufficient genotype data for estimating an odds ratio (OR) with 95\% confidence interval (CI); (5) genotype distributions of controls passed Hardy-Weinberg equilibrium (HWE) test.

Accordingly, the following exclusion criteria were also used: (1) the design of the experiments were not casecontrol studies; (2) the source of cases and controls, and other essential information were not provided; (3) the genotype distribution of the control population was departure from HWE; (4) reviews, meta-analysis and duplicated publications.

\section{Data extraction and synthesis}

Information was carefully extracted from all eligible studies independently by two authors according to the inclusion criteria listed above. In case of disagreements, another author was consulted to resolve the dispute, and a final decision was made by the majority of the votes. For each included study, the following information was collected: first author, year of publication, country of origin, ethnicity, source of control, numble of cases and controls, genotype methods, allele and genotype frequencies and evidence of HWE in controls. Different ethnicity descents were categorized as Caucasian, Asian, and "mixed". All the case and control groups were well controlled. The non-cancer controls had no history of gynecologic disease, and there was no present evidence of any malignant disease.

\section{Statistical analysis}

The associations between AURKA polymorphisms and $\mathrm{BC}$ risk were measured by odds ratio (OR) with $95 \%$ confidence interval $(\mathrm{CI})$. The significance of the pooled OR was determined by the $\mathrm{Z}$ test. Statistical heterogeneity among studies was assessed with the $Q$ and $I^{2}$ statistics. If the $P$ value of heterogeneity test was more than 0.1 $(P \geq 0.1)$, the pooled OR estimate of the study was calculated by the fixed-effects model. Otherwise, the randomeffects model was used [26]. The value of the I index is used to assess the degree of heterogeneity $\left(\mathrm{I}^{2}<25 \%\right.$ : no heterogeneity; $25 \%<\mathrm{I}^{2}<50 \%$ : moderate heterogeneity; $50 \%<\mathrm{I}^{2}<75 \%$ : high heterogeneity; $\mathrm{I}^{2}>75 \%$ :extreme 
105 potential relevant studies from PubMed,

Web of Knowledge and Embase

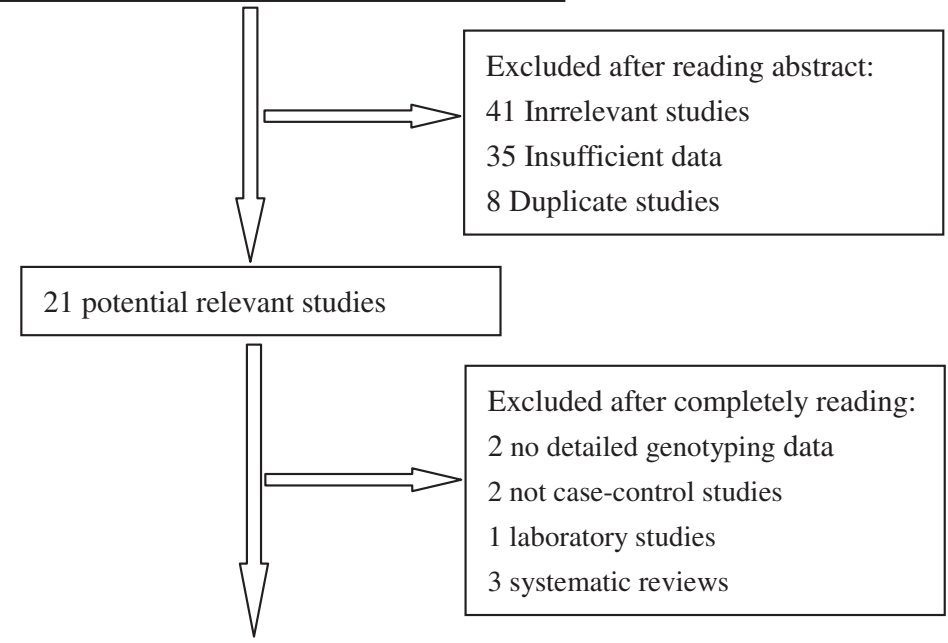

13 studies were finally identified in this

meta-analysis

Figure 1 Flow chart of studies selection in this meta-analysis.

Table 1 Characteristics of the studies included in the meta-analysis

\begin{tabular}{|c|c|c|c|c|c|c|c|c|}
\hline First author & Year & Country & Ethnicity & Design & Genotyping medthod & Number(case/control) & SNP & HWE \\
\hline Ruan [13] & 2011 & China & Asian & $\mathrm{PB}$ & TaqMan & $1334 / 1568$ & rs2273535 & 0.76 \\
\hline Shi [14] & 2011 & Sweden & Caucasian & PB & TaqMan & $763 / 1516$ & rs2273535 & 0.23 \\
\hline \multirow[t]{2}{*}{ MARIE-GENICA [15] } & 2010 & German & Caucasian & $\mathrm{PB}$ & MALDI-TOF & $3137 / 5469$ & rs2273535 & 0.12 \\
\hline & & & & & & & rs1047972 & 0.17 \\
\hline Couch [16] & 2007 & CIMBA & Mixed & $\mathrm{PB}$ & TaqMan & $3884 / 3303$ & rs2273535 & NA \\
\hline Tchatchou [17] & 2007 & German & Caucasian & PB & TaqMan & $727 / 819$ & rs2273535 & 0.60 \\
\hline Vidarsdottir [18] & 2007 & Iceland & Caucasian & NA & PCR-RFLP & $759 / 653$ & rs2273535 & 0.07 \\
\hline \multirow[t]{2}{*}{ Cox [19] } & 2006 & USA & Caucasian & NA & TaqMan & $1259 / 1742$ & rs2273535 & 0.31 \\
\hline & & & & & & & rs1047972 & 0.70 \\
\hline Fletcher [20] & 2006 & UK & Caucasian & $\mathrm{PB}$ & PCR-RFLP & $507 / 875$ & rs2273535 & 0.13 \\
\hline Ewart-Toland [21] & 2005 & USA & Mixed & PB & SnAPSHOT & $898 / 448$ & rs2273535 & 0.81 \\
\hline \multirow[t]{2}{*}{ Lo [22] } & 2005 & China(Taiwan) & Asian & $\mathrm{HB}$ & TaqMan & 709/1972 & rs2273535 & 0.23 \\
\hline & & & & & & & rs1047972 & 0.80 \\
\hline \multirow[t]{2}{*}{ Dai [23] } & 2004 & China & Asian & PB & TaqMan & $1102 / 1188$ & rs2273535 & 0.07 \\
\hline & & & & & & & rs1047972 & 0.68 \\
\hline \multirow[t]{2}{*}{ Egan [24] } & 2004 & USA & Caucasian & $\mathrm{PB}$ & Sequencing & $941 / 830$ & rs2273535 & 0.31 \\
\hline & & & & & & & rs 1047972 & 0.68 \\
\hline Sun [25] & 2004 & China & Asian & $\mathrm{HB}$ & PCR-RFLP & $520 / 520$ & rs 2273535 & 0.11 \\
\hline
\end{tabular}

HWE: Hardy-Weinberg equilibrium; PB: population based; HB: hospital-based; NA: not available; PCR: polymerase chain reaction; RFLP: restriction fragment length polymorphism; MALDI-TOF MS: Matrix-Assisted Laser Desorption/lonization Time of Flight Mass Spectrometry; CIMBA: the Consortium of Investigators of Modifiers of BRCA1/2 including 16 clinic and population-based research studies and multicenter consortia. 
high heterogeneity). Publication bias were evaluated by the funnel plot and further assessed by the method of Egger's linear regression test. All statistical analyses were carried out with the review manager version 5.1 (Revman; The Cochrane Collaboration, Oxford, UK).

\section{Results}

\section{Characteristics of eligible studies}

As shown in Figure 1, a total of 105 potential publications were extracted at first based on our selection strategy. According to the inclusion criteria defined above, 13 studies on AURKA polymorphisms and BC risk were finally identified in this meta-analysis [13-25]. These studies included 16,349 BC patients and 20,872 cancer-free controls. The characteristics of the included studies are listed in Tables 1. Among the eligible thirteen studies, seven studies were performed in Caucasians from Sweden, Germany, Iceland, UK and USA [14,15,17-20,24]. Four were based on Asian background and were carried out in China $[13,22,23,25]$. Two studies were mixed ethnicity descent [16,21]. All studies were case-control studies. All BC cases were confirmed by histology or pathology. Moreover, controls were mainly matched on age, of which nine were population-based and two were hospital-based studies.

\section{Meta-analysis results}

As shown in Table 2, the frequencies of the minor allele in $\mathrm{BC}$ patients varied widely across the eligible studies, ranging from 0.19 to 0.82 (rs2273535), 0.13 to 0.16 (rs1047972). The average frequencies of the minor allele in the two polymorphisms were 0.39 and 0.15 , respectively.

The main results of this meta-analysis were listed in Table 3. There were 13 studies with 16,286 BC patients and 20,689 case-free controls for AURKA rs2273535 polymorphism. As show in Table 3 and Figure 2, there was significant association between rs2273535 and BC risk in three genetic models in the overall population (A vs. $\mathrm{T}$ : $\mathrm{OR}=1.08,95 \% \mathrm{CI}=1.01-1.15, P=0.02$; $\mathrm{AA}$ vs. TT: $\mathrm{OR}=1.36,95 \% \mathrm{CI}=1.06-1.73, P<0.00001 ;$ AA vs. TT + TA: $\mathrm{OR}=1.15,95 \% \mathrm{CI}=1.01-1.31, P=0.04$ ), while there was no significant association in heterozygote comparison and the dominant model (TA vs. TT: $\mathrm{OR}=1.02$, $95 \% \mathrm{CI}=0.96-1.08, P=0.52$; $\mathrm{TA}+\mathrm{AA}$ vs. $\mathrm{TT}: \mathrm{OR}=1.04$, $95 \% \mathrm{CI}=0.98-1.09, P=0.20$ ). In the subgroup analysis by ethnicity, the effects remained in Asians (allele contrast

Table 2 AURKA polymorphisms genotype distribution and allele frequency in cases and controls

\begin{tabular}{|c|c|c|c|c|c|c|c|c|c|c|c|c|c|}
\hline \multirow[t]{3}{*}{ First author } & \multicolumn{8}{|c|}{ Genotype (N) } & \multicolumn{4}{|c|}{ Allele frequency (N) } & \multirow{3}{*}{$\begin{array}{l}\text { MAF } \\
\text { (Case/Control) }\end{array}$} \\
\hline & \multicolumn{4}{|l|}{ Case } & \multicolumn{4}{|c|}{ Control } & \multicolumn{2}{|l|}{ Case } & \multicolumn{2}{|c|}{ Control } & \\
\hline & Total & AA & $\mathrm{Aa}$ & $\overline{\text { aa }}$ & Total & AA & $\mathrm{Aa}$ & aa & $\bar{A}$ & a & $\bar{A}$ & $\mathrm{a}$ & \\
\hline \multicolumn{14}{|l|}{ rs2273535 (T > A) } \\
\hline Ruan 2011 & 1334 & 599 & 568 & 167 & 1568 & 716 & 691 & 161 & 1766 & 902 & 2123 & 1013 & $0.34 / 0.32$ \\
\hline Shi 2011 & 763 & 27 & 222 & 514 & 1516 & 71 & 478 & 967 & 276 & 1250 & 620 & 2412 & $0.82 / 0.80$ \\
\hline MARIE-GENICA 2010 & 3076 & 1873 & 1096 & 107 & 5466 & 3290 & 1927 & 249 & 4842 & 1310 & 8507 & 2425 & $0.21 / 0.22$ \\
\hline Couch 2007 & 3884 & 3696 & & 188 & 3303 & 3128 & & 175 & - & - & - & - & - \\
\hline Tchatchou 2007 & 727 & 37 & 257 & 433 & 819 & 47 & 287 & 485 & 331 & 1123 & 381 & 1257 & $0.77 / 0.77$ \\
\hline Vidarsdottir 2007 & 759 & 429 & 288 & 42 & 653 & 401 & 231 & 21 & 1146 & 372 & 1033 & 273 & $0.25 / 0.21$ \\
\hline Cox 2006 & 1241 & 774 & 401 & 66 & 1711 & 1075 & 571 & 65 & 1949 & 533 & 2721 & 701 & $0.22 / 0.21$ \\
\hline Fletcher 2006 & 507 & 335 & 154 & 18 & 875 & 547 & 280 & 48 & 824 & 190 & 1374 & 376 & $0.19 / 0.22$ \\
\hline Ewart-Toland 2005 & 898 & 533 & 303 & 62 & 448 & 279 & 148 & 21 & 1369 & 427 & 706 & 190 & $0.24 / 0.21$ \\
\hline Lo 2005 & 707 & 71 & 288 & 348 & 1969 & 196 & 887 & 886 & 430 & 984 & 1279 & 2659 & $0.70 / 0.68$ \\
\hline Dai 2004 & 1102 & 121 & 491 & 490 & 1186 & 149 & 503 & 534 & 733 & 1471 & 801 & 1571 & $0.67 / 0.66$ \\
\hline Egan 2004 & 940 & 559 & 331 & 50 & 830 & 516 & 283 & 31 & 1449 & 431 & 1315 & 345 & $0.23 / 0.21$ \\
\hline Sun 2004 & 520 & 50 & 214 & 256 & 520 & 66 & 262 & 192 & 314 & 726 & 394 & 646 & $0.70 / 0.62$ \\
\hline \multicolumn{14}{|l|}{ rs1047972 (G > A) } \\
\hline MARIE-GENICA 2010 & 3139 & 2220 & 850 & 69 & 5469 & 3737 & 1561 & 171 & 5290 & 988 & 9035 & 1903 & $0.16 / 0.17$ \\
\hline Cox 2006 & 1240 & 870 & 342 & 28 & 1724 & 1215 & 462 & 47 & 2082 & 398 & 2892 & 556 & $0.16 / 0.16$ \\
\hline Lo 2005 & 704 & 543 & 146 & 15 & 1950 & 1506 & 414 & 30 & 1232 & 176 & 3426 & 474 & $0.13 / 0.12$ \\
\hline Dai 2004 & 1102 & 805 & 281 & 16 & 1188 & 908 & 263 & 17 & 1891 & 313 & 2079 & 297 & $0.14 / 0.13$ \\
\hline Egan 2004 & 905 & 637 & 245 & 23 & 788 & 542 & 225 & 21 & 1519 & 291 & 1309 & 267 & $0.16 / 0.17$ \\
\hline
\end{tabular}

A represents the major allele, a represents the minor allele. MAF: minor allele frequencies. 
Table 3 Meta-analysis results

\begin{tabular}{|c|c|c|c|c|c|c|}
\hline \multirow[t]{2}{*}{ Comparisons } & \multirow[t]{2}{*}{ OR } & \multirow[t]{2}{*}{$95 \% \mathrm{Cl}$} & \multirow[t]{2}{*}{$P$ value } & \multicolumn{2}{|c|}{ Heterogeneity } & \multirow{2}{*}{$\begin{array}{l}\text { Effects } \\
\text { model }\end{array}$} \\
\hline & & & & $1^{2}$ & $P$ value & \\
\hline \multicolumn{7}{|l|}{ a vs $A$} \\
\hline rs2273535 & 1.08 & $1.01-1.15$ & 0.02 & $62 \%$ & 0.002 & R \\
\hline Caucasian & 1.05 & $0.96-1.14$ & 0.31 & $63 \%$ & 0.01 & R \\
\hline Asian & 1.12 & $1.00-1.26$ & 0.04 & $66 \%$ & 0.03 & $R$ \\
\hline rs1047972 & 0.98 & $0.89-1.08$ & 0.75 & $55 \%$ & 0.06 & $\mathrm{R}$ \\
\hline Caucasian & 0.92 & $0.86-0.98$ & 0.01 & $0 \%$ & 0.38 & $\mathrm{~F}$ \\
\hline Asian & 1.10 & $0.97-1.25$ & 0.14 & $0 \%$ & 0.37 & $\mathrm{~F}$ \\
\hline \multicolumn{7}{|l|}{ aa vs AA } \\
\hline rs2273535 & 1.36 & $1.06-1.73$ & $<0.00001$ & $82 \%$ & $<0.00001$ & $\mathrm{R}$ \\
\hline Caucasian & 1.32 & $0.85-2.03$ & 0.21 & $88 \%$ & $<0.00001$ & $\mathrm{R}$ \\
\hline Asian & 1.22 & $1.06-1.41$ & 0.007 & $24 \%$ & 0.27 & $\mathrm{~F}$ \\
\hline rs1047972 & 0.81 & $0.66-0.99$ & 0.04 & $22 \%$ & 0.28 & F \\
\hline Caucasian & 0.74 & $0.59-0.93$ & 0.009 & $0 \%$ & 0.56 & $\mathrm{~F}$ \\
\hline Asian & 1.22 & $0.77-1.95$ & 0.40 & $0 \%$ & 0.57 & F \\
\hline \multicolumn{7}{|l|}{ Aa vs AA } \\
\hline rs2273535 & 1.02 & $0.96-1.08$ & 0.52 & $0 \%$ & 0.83 & $\mathrm{~F}$ \\
\hline Caucasian & 1.02 & $0.95-1.09$ & 0.64 & $0 \%$ & 0.67 & $\mathrm{~F}$ \\
\hline Asian & 1.02 & $0.90-1.14$ & 0.80 & $0 \%$ & 0.49 & $\mathrm{~F}$ \\
\hline rs1047972 & 0.98 & $0.91-1.05$ & 0.51 & $41 \%$ & 0.14 & $\mathrm{~F}$ \\
\hline Caucasian & 0.94 & $0.87-1.02$ & 0.15 & $0 \%$ & 0.46 & $\mathrm{~F}$ \\
\hline Asian & 1.10 & $0.95-1.26$ & 0.20 & $51 \%$ & 0.15 & F \\
\hline \multicolumn{7}{|l|}{$A a+$ aa vs $A A$} \\
\hline rs2273535 & 1.04 & $0.98-1.09$ & 0.20 & $12 \%$ & 0.33 & F \\
\hline Caucasian & 1.02 & $0.95-1.08$ & 0.61 & $31 \%$ & 0.19 & $\mathrm{~F}$ \\
\hline Asian & 1.07 & $0.96-1.20$ & 0.21 & $0 \%$ & 0.48 & F \\
\hline rs1047972 & 0.99 & $0.89-1.10$ & 0.84 & $51 \%$ & 0.09 & $\mathrm{R}$ \\
\hline Caucasian & 0.92 & $0.86-1.00$ & 0.04 & $0 \%$ & 0.40 & $\mathrm{~F}$ \\
\hline Asian & 1.10 & $0.96-1.27$ & 0.16 & $33 \%$ & 0.22 & $\mathrm{~F}$ \\
\hline \multicolumn{7}{|l|}{ aa vs $A A+A a$} \\
\hline rs2273535 & 1.15 & $1.01-1.31$ & 0.04 & $69 \%$ & 0.0001 & $\mathrm{R}$ \\
\hline Caucasian & 1.13 & $0.92-1.38$ & 0.24 & $66 \%$ & 0.007 & $\mathrm{R}$ \\
\hline Asian & 1.23 & $1.10-1.50$ & 0.05 & $76 \%$ & 0.006 & $\mathrm{R}$ \\
\hline rs1047972 & 0.82 & $0.67-1.00$ & 0.05 & $14 \%$ & 0.33 & $\mathrm{~F}$ \\
\hline Caucasian & 0.75 & $0.60-0.94$ & 0.01 & $0 \%$ & 0.60 & $\mathrm{~F}$ \\
\hline Asian & 1.20 & $0.75-1.91$ & 0.44 & $0 \%$ & 0.50 & $\mathrm{~F}$ \\
\hline
\end{tabular}

A: represents the major allele, a: represents the minor allele, F: fixed effects model, R: random effects model.

genetic model: $\mathrm{OR}=1.12,95 \% \mathrm{CI}=1.00-1.26, P=0.04$ and homozygote comparison: $\mathrm{OR}=1.22,95 \% \mathrm{CI}=1.06-1.41$, $P=0.007)$. However, no genetic models reached statistical association in Cauasians (Table 3).

5 studies with 7,090 cases and 11,119 controls were used to assess the relationship between rs1047972 polymorphism and $\mathrm{BC}$ risk. As shown in Table 3 and Figure 3, rs1047972 polymorphism was associated with BC risk in the overall population based on homozygote comparison (AA vs. GG: $\mathrm{OR}=0.81,95 \% \mathrm{CI}=0.66-0.99, \quad P=0.04$ ). There was no association in these four genetic models (allele contrast genetic model: $\mathrm{OR}=0.98,95 \% \mathrm{CI}=0.89-1.08$, $P=0.75$; heterozygote comparison: $\mathrm{OR}=0.98,95 \% \mathrm{CI}=$ 0.91-1.05, $P=0.51$; dominant model: $\mathrm{OR}=0.99,95 \% \mathrm{CI}=$ $0.89-1.10, P=0.84)$; recessive model $(\mathrm{OR}=0.82,95 \% \mathrm{CI}=$ 0.67-1.00, $P=0.05)$. When stratified by ethnicity, rs1047972 polymorphism had a decreased association with BC risk in Caucasians based on allele contrast genetic model: $\mathrm{OR}=0.92,95 \% \mathrm{CI}=0.86-0.98, P=0.01$; homozygote comparison: $\mathrm{OR}=0.74,95 \% \mathrm{CI}=0.59-0.93, P=$ 0.009; dominant model: $\mathrm{OR}=0.92,95 \% \mathrm{CI}=0.86-1.00$, $P=0.04)$; recessive model $(\mathrm{OR}=0.75,95 \% \mathrm{CI}=0.60-0.94$, $P=0.01)$. However, there was no association in any genetic model in Asians.

\section{Publication bias}

Begg's funnel plot and Egger's test were performed to assess the publication bias. As shown in Figure 4, the funnel plots did not reveal any obvious asymmetry in all genotypes in overall population, and the results of Egger's test revealed no publication bias $(P>0.05)$.

\section{Discussion}

AURKA is associated with centrosomes, being localized at the centrosome just prior to the onset of mitosis and for the duration of mitosis. Overexpression of AURKA leads to centrosome amplification and cellular transformation [27]. This threonine kinase belongs to a family of mitotic kinases that maintain chromosomal stability through phosphorylation. Thus, any severe defects in AURKA, such as mutations, would lead to drastic genomic instability and induce apoptosis through cell cycle checkpoint surveillance $[11,28]$. Consequently, the cell harboring a defective AURKA may lead to cancer [11].

Epidemiological studies have been performed to assess the association of AURKA polymorphisms (rs2273535 and rs1047972) with $\mathrm{BC}$ risk. However, the results are conflicting. Thus, we conducted a comprehensive metaanalysis involving published data, to assess the strength of association between the two polymorphisms and BC risk. In this present meta-analysis, 13 studies with 16,286 $\mathrm{BC}$ patients and 20,689 case-free controls concerning the rs2273535 polymorphism, 5 studies with 7,090 cases and 11,119 controls concerning the rs1047972 polymorphism, were included, respectively. And we explored the association between the two potentially functional polymorphisms of AURKA and BC risk.

In the overall population, we found that rs2273535 polymorphism had an increased association with $\mathrm{BC}$ risk in three genetic models (allele contrast genetic model: $\mathrm{OR}=1.08,95 \% \mathrm{CI}=1.01-1.15, \quad P=0.02$; homozygote 


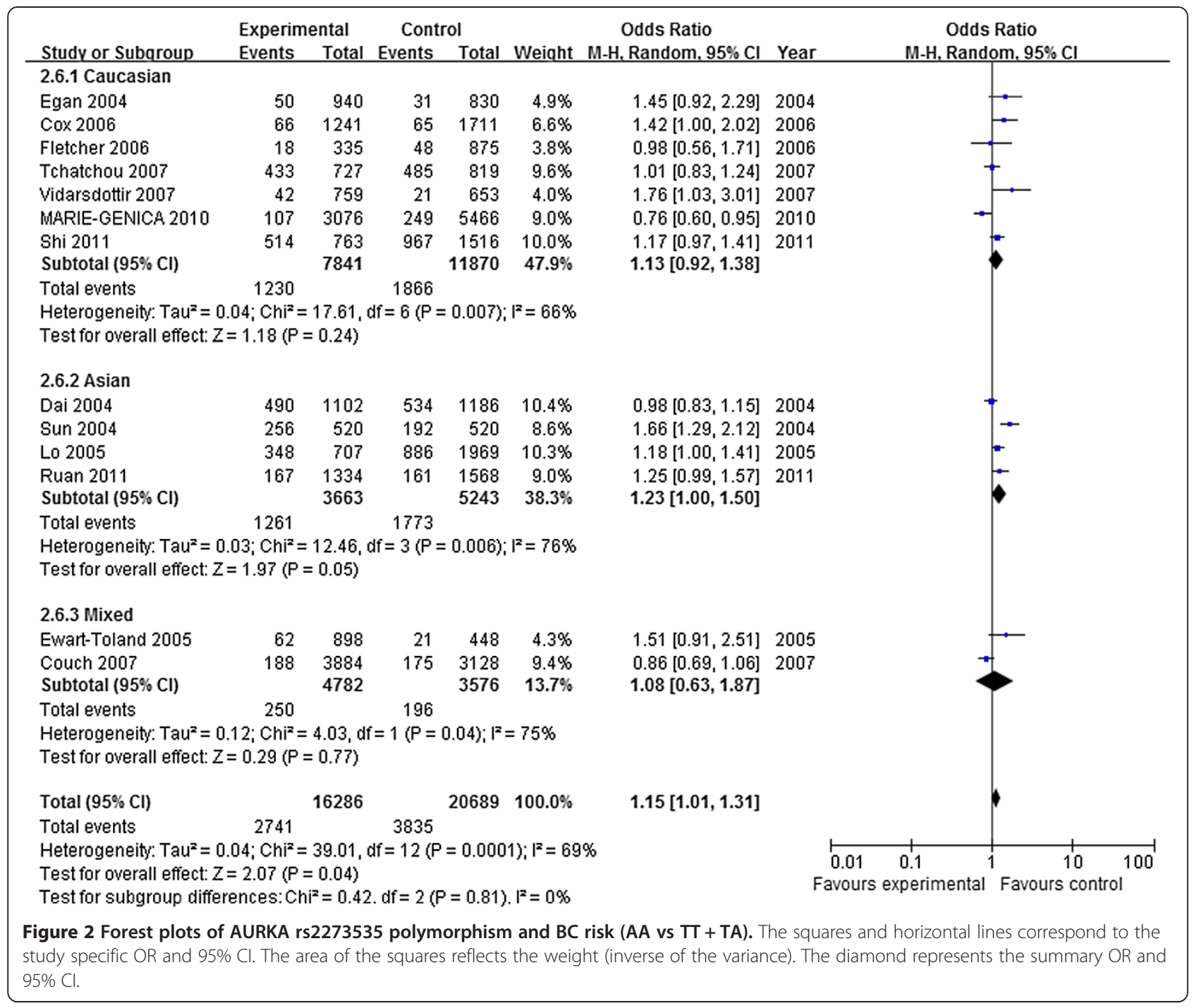

comparison: $\mathrm{OR}=1.36,95 \% \mathrm{CI}=1.06-1.73, P<0.00001$; recessive model: $\mathrm{OR}=1.15,95 \% \mathrm{CI}=1.01-1.31, P=0.04$ ). However, rs1047972 polymorphism had a decreased association with $\mathrm{BC}$ risk based on homozygote comparison $(\mathrm{OR}=0.81,95 \% \mathrm{CI}=0.66-0.99, P=0.04)$.

In the stratified analysis based on ethnicity, rs2273535 polymorphism had increased BC risk in Asians based on allele contrast genetic model, homozygote comparison, and the recessive model. However, no genetic models reached statistical association in Cauasians. For rs1047972 polymorphism, there was no significant association in Asians. Rs1047972 had a decreased BC risk in Caucasians based on allele contrast genetic model, homozygote comparison, the dominant model, and the recessive model.

In a previous meta-analysis by Qin et al. [29], they failed to find any significant association between rs1047972 polymorphism and $\mathrm{BC}$ risk. It is worth mentioning, the results of the present study are not in accordance with Qin's analysis. This discrepancy may result from different sample size and ethnic groups. There were only seven studies including 5966 cases and 7609 controls in Qin's meta-analysis [29], while 13 studies (16,349 BC patients and 20,872 case-free controls) were involved in our meta-analysis.

There are some limitations in this meta-analysis. Firstly, this meta-analysis was based on pooled data. We could not assess the risk of cancer according to stratification of age, smoking, alcohol consumption, environment factors, and other risk factors. Secondly, no individual data such as pathological type, histologic grade, and other clinicopathological index was available. Thus, we could not assess the clinicopathological significance of the polymorphisms in BC. Thirdly, there were only published studies including in the meta-analysis. It is possible that some related unpublished studies that might meet the inclusion criteria were missed. Finally, the included studies were mainly based on Caucasian background. There were only four studies based on Asian background 


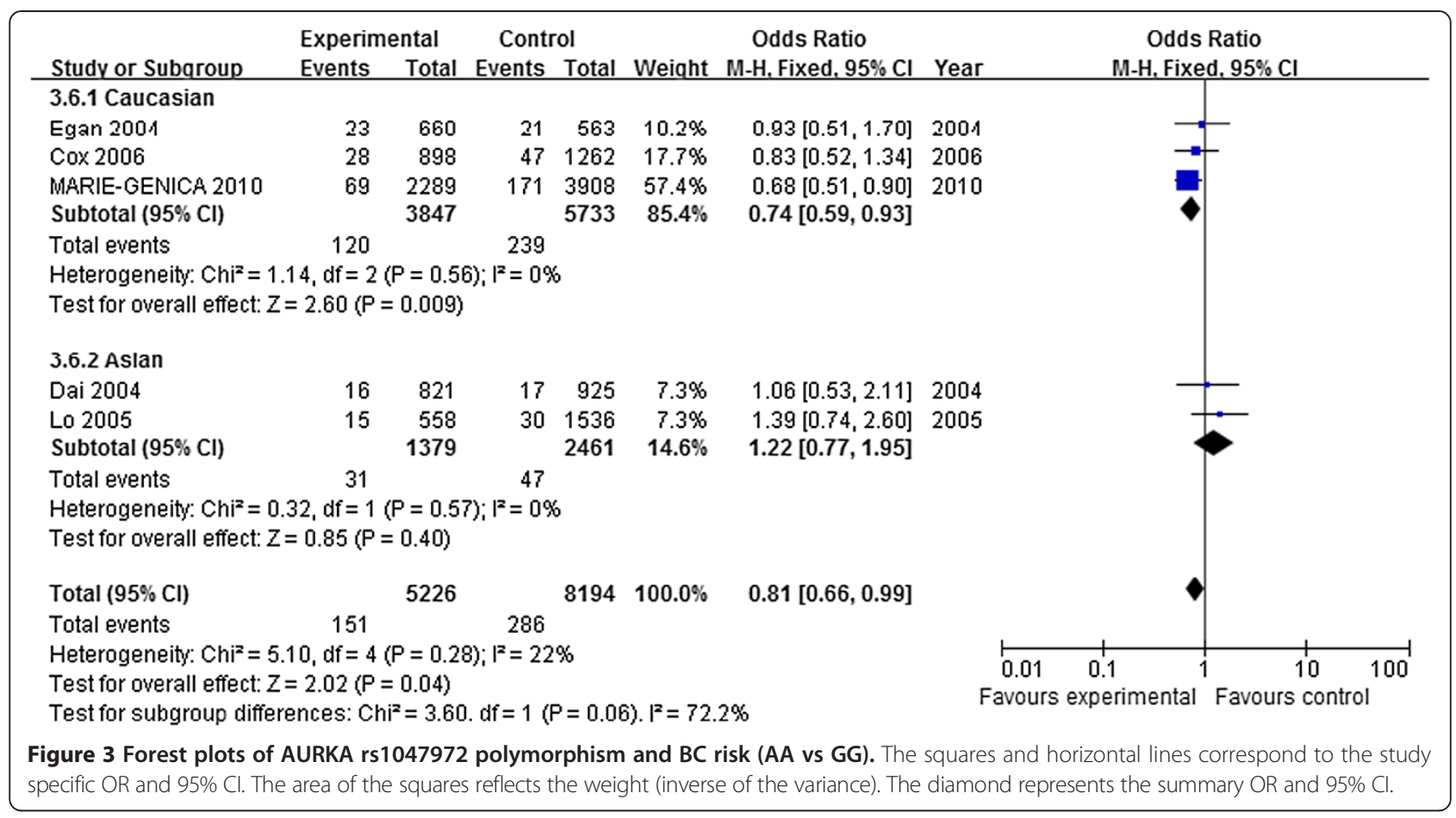

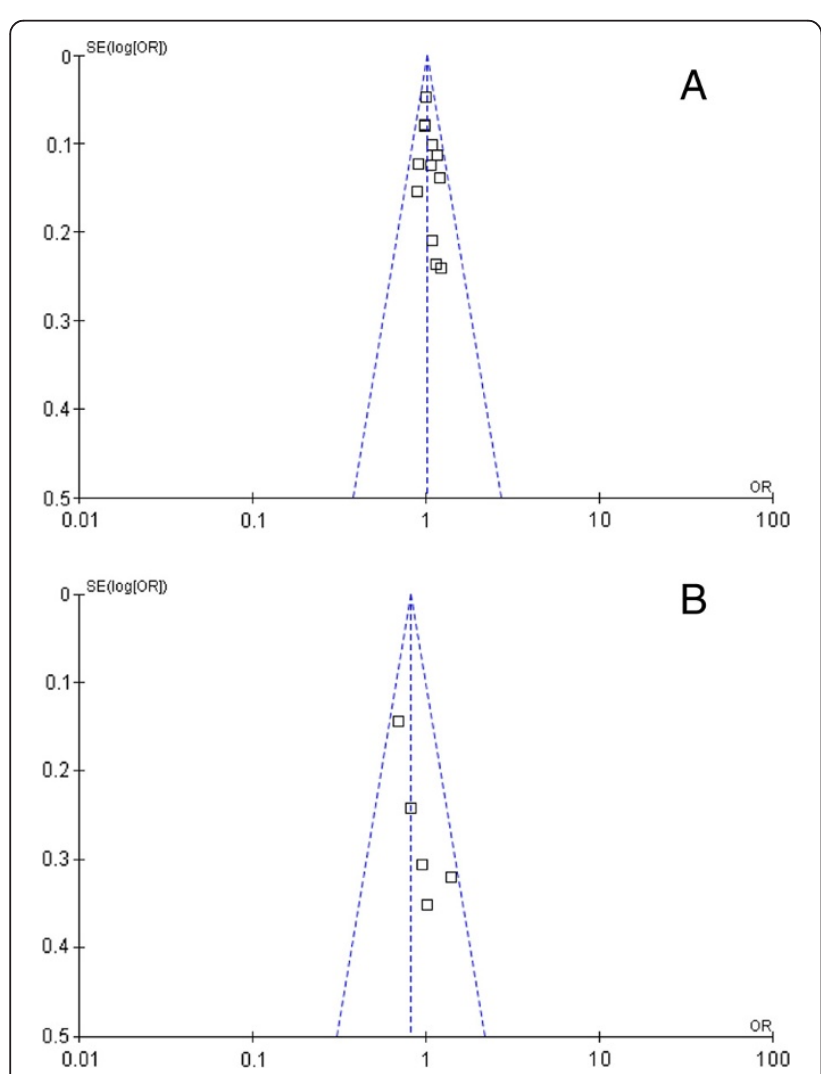

Figure 4 Funnel plot assessing evidence of publication bias from the eligible studies. A: F31I (rs2273535); B: V57l (rs1047972). and none based on African background. Further large scale multicenter studies based on Asian or African are warranted to further validate on AURKA polymorphisms and $\mathrm{BC}$ risk.

\section{Conclusion}

In summary, this meta-analysis suggests that AURKA rs2273535 polymorphism has an increased risk with $\mathrm{BC}$, especially in Asians. However, rs1047972 polymorphism has a decreased BC risk in Caucasians. Our results indicate that AURKA rs2273535 is a candidate gene polymorphism, and rs1047972 polymorphism is a protective factor for $\mathrm{BC}$ cancer risk. We conclude that the two polymorphisms may be potential biomarkers in diagnosis and prediction of $\mathrm{BC}$ risk. Further large scale epidemiological studies are needed to confirm these findings.

\section{Competing interest}

The authors declare that they have no competing interests.

\section{Authors' contributions}

DZJ and LXX designed the research. DZJ, WXJ, KHF and LS performed the experiments throughout this research. ZY, RHT, MWL and WXJ participated in its design and coordination. LS and WM analyzed the data; DZJ, KHF and SYP contributed to the writing of the manuscript. Co-first authors: DZJ, KHF and WXJ. All authors have read and approved the final manuscript.

\section{Acknowledgments}

This study was supported by the International Cooperative Project of Shaanxi province, People's Republic of China (No. 2013KW-32-01); China Postdoctoral Science Foundation; the Fundamental Research Funds for the Central Universities, China and Specialized Research Fund of the Second Affiliated Hospital of Xi'an Jiaotong University, China [RC (GG) 201203]. 


\section{Author details}

'Department of Oncology, the Second Affiliated Hospital of Xi'an Jiaotong University, Xi'an 710004, China. ${ }^{2}$ Center for Translational Medicine, Frontier Institute of Science and Technology (FIST), Xi'an Jiaotong University, Xi'an 710049, China.

Received: 25 June 2014 Accepted: 1 September 2014

Published: 5 September 2014

\section{References}

1. Siegel R, Naishadham D, Jemal A: Cancer statistics, 2013. CA Cancer J Clin 2013, 63:11-30.

2. Lo PK, Sukumar S: Epigenomics and breast cancer. Pharmacogenomics 2008, 9:1879-1902.

3. Lichtenstein P, Holm NV, Verkasalo PK, Iliadou A, Kaprio J, Koskenvuo M, Pukkala E, Skytthe A, Hemminki K: Environmental and heritable factors in the causation of cancer analyses of cohorts of twins from Sweden, Denmark, and Finland. N Engl J Med 2000, 343:78-85.

4. Hemminki K, Granstrom C, Czene K: Attributable risks for familial breast cancer by proband status and morphology: a nationwide epidemiologic study from Sweden. Int. J. Cancer 2002, 100:214-219.

5. Carvajal RD, Tse A, Schwartz GK: Aurora kinases: new targets for cancer therapy. Clin Cancer Res 2006, 12:6869-6875

6. Castro A, Arlot-Bonnemains Y, Vigneron S, Labbé JC, Prigent C, Lorca T: APC/Fizzy-Related targets Aurora-A kinase for proteolysis. EMBO Rep 2002, 3:457-462.

7. Fu J, Bian $M$, Jiang Q, Zhang C: Roles of Aurora kinases in mitosis and tumorigenesis. Mol Cancer Res 2007, 5:1-10.

8. Gritsko TM, Coppola D, Paciga JE, Yang L, Sun M, Shelley SA, Fiorica JV Nicosia SV, Cheng JQ: Activation and overexpression of centrosome kinase BTAK/Aurora-A in human ovarian cancer. Clin Cancer Res 2003, 9:1420-1426.

9. Fraizer GC, Diaz MF, Lee IL, Grossman HB, Sen S: Aurora-A/STK15/ BTAK enhances chromosomal instability in bladder cancer cells. Int J Oncol 2004, 25:1631-1639.

10. Kamada K, Yamada Y, Hirao T, Fujimoto H, Takahama Y, Ueno M, Takayama T, Naito A, Hirao S, Nakajima Y: Amplification/overexpression of Aurora-A in human gastric carcinoma: potential role in differentiated type gastric carcinogenesis. Oncol Rep 2004, 12:593-599.

11. Goepfert TM, Adigun YE, Zhong L, Gay J, Medina D, Brinkley WR: Centrosome amplification and overexpression of aurora $A$ are early events in rat mammary carcinogenesis. Cancer Res 2002, 62:4115-4122.

12. Ewart-Toland A, Briassouli P, de Koning JP, Mao JH, Yuan J, Chan F, MacCarthy-Morrogh L, Ponder BA, Nagase H, Burn J, Ball S, Almeida M, Linardopoulos S, Balmain A: Identification of Stk6/STK15 as a candidate low-penetrance tumor susceptibility gene in mouse and human. Nat Genet 2003, 34:403-412.

13. Ruan $Y$, Song AP, Wang $H$, Xie $Y T$, Han JY, Sajdik C, Tian XX, Fang WG: Genetic polymorphisms in AURKA and BRCA1 are associated with breast cancer susceptibility in a Chinese Han population. J Pathol 2011, 225:535-543.

14. Shi H, Bevier M, Johansson R, Grzybowska E, Chen B, Eyfjörd JE, Hamann U, Manjer J, Enquist K, Henriksson R, Carlson J, Brandt A, Lascorz J, Butkiewicz D, Pamula-Pilat J, Tecza K, Herms S, Hoffmann P, Hemminki K, Lenner P, Försti A: Single nucleotide polymorphisms in the $20 q 13$ amplicon genes in relation to breast cancer risk and clinical outcome. Breast Cancer Res Treat 2011, 130:905-916.

15. MARIE-GENICA Consortium: Polymorphisms in the BRCA1 and ABCB1 genes modulate menopausal hormone therapy associated breast cancer risk in postmenopausal women. Breast Cancer Res Treat 2010, 120:727-736.

16. Couch FJ, Sinilnikova O, Vierkant RA, Pankratz VS, Fredericksen ZS, StoppaLyonnet D, Coupier I, Hughes D, Hardouin A, Berthet P, Peock S, Cook M, Baynes C, Hodgson S, Morrison PJ, Porteous ME, Jakubowska A, Lubinski J, Gronwald J, Spurdle AB, kConFab, Schmutzler R, Versmold B, Engel C, Meindl A, Sutter C, Horst J, Schaefer D, Offit K, Kirchhoff T, et al: AURKA F31I polymorphism and breast cancer risk in BRCA1 and BRCA2 mutation carriers: a consortium of investigators of modifiers of BRCA1/2 study. Cancer Epidemiol Biomarkers Prev 2007, 16:1416-1421.

17. Tchatchou S, Wirtenberger M, Hemminki K, Sutter C, Meindl A, Wappenschmidt B, Kiechle M, Bugert P, Schmutzler RK, Bartram CR,
Burwinkel B: Aurora kinases A and B and familial breast cancer risk. Cancer Lett 2007, 247:266-272.

18. Vidarsdottir L, Bodvarsdottir SK, Hilmarsdottir $H$, Tryggvadottir L, Eyfjord JE: Breast cancer risk associated with AURKA $91 \mathrm{~T}>\mathrm{A}$ polymorphism in relation to BRCA mutations. Cancer Lett 2007, 250:206-212.

19. Cox DG, Hankinson SE, Hunter DJ: Polymorphisms of the AURKA (STK15/ Aurora Kinase) gene and breast cancer risk (United States). Cancer Causes Control 2006, 17:81-83.

20. Fletcher O, Johnson N, Palles C, dos Santos Silva I, McCormack V, Whittaker J, Ashworth A, Peto J: Inconsistent associ-ation between the STK15 F31I genetic polymorphism and breast cancer risk. J Natl Cancer Inst 2006, 98:1014-1018.

21. Ewart-Toland A, Dai Q, Gao YT, Nagase H, Dunlop MG, Farrington SM, Barnetson RA, Anton-Culver H, Peel D, Ziogas A, Lin D, Miao X, Sun T, Ostrander EA, Stanford JL, Langlois M, Chan JM, Yuan J, Harris CC, Bowman ED, Clayman GL, Lippman SM, Lee JJ, Zheng W, Balmain A: Aurora-A/STK15 T91A is a general low penetrance cancer susceptibility gene: a meta-analysis of multiple cancer types. Carcinogenesis 2005, 26:1368-1373.

22. Lo YL, Yu JC, Chen ST, Yang HC, Fann CS, Mau YC, Shen CY: Breast cancer risk associated with genotypic polymor-phism of the mitosis-regulating gene Aurora-A/STK15/BTAK. Int J Cancer 2005, 115:276-283.

23. Dai Q, Cai QY, Shu XO, Ewart-Toland A, Wen WQ, Balmain A, Gao YT, Zheng W: Synergistic effects of STK15 gene polymorphisms and endogenous estrogen exposure in the risk of breast cancer. Cancer Epidemiol Biomarkers Prev 2004, 13:2065-2070.

24. Egan KM, Newcomb PA, Ambrosone CB, Trentham-Dietz A, Titus-Ernstoff L, Hampton JM, Kimura MT, Nagase H: STK15 polymorphism and breast cancer risk in a population-based study. Carcinogenesis 2004 , 25:2149-2153.

25. Sun T, Miao X, Wang J, Tan W, Zhou Y, Yu C, Lin D: Functional Phe31lle polymorphism in Aurora A and risk of breast carcinoma. Carcinogenesis 2004, 25:2225-2230.

26. Dai ZJ, Wang XJ, Zhao Y, Ma XB, Kang HF, Min WL, Lin S, Yang PT, Liu XX: Effects of interleukin-10 polymorphisms (rs1800896, rs1800871 and rs1800872) on breast cancer risk: evidence from an update meta-analysis. Genet Test Mol Biomarkers 2014, 18:439-445.

27. Lukasiewicz KB, Lingle WL: Aurora A, centrosome structure, and the centrosome cycle. Environ Mol Mutagen 2009, 50:602-619.

28. Marumoto T, Zhang D, Saya H: Aurora-A - a guardian of poles. Nat Rev Cancer 2005, 5:42-50.

29. Qin K, Wu C, Wu X: Two nonsynonymous polymorphisms (F31I and V57I) of the STK15 gene and breast cancer risk: a meta-analysis based on 5966 cases and 7609 controls. J Int Med Res 2013, 41:956-963.

\section{doi:10.1186/s12935-014-0091-y}

Cite this article as: Dai et al:: Association between genetic polymorphisms in AURKA (rs2273535 and rs1047972) and breast cancer risk: a meta-analysis involving 37,221 subjects. Cancer Cell International 2014 14:91.

\section{Submit your next manuscript to BioMed Central and take full advantage of:}

- Convenient online submission

- Thorough peer review

- No space constraints or color figure charges

- Immediate publication on acceptance

- Inclusion in PubMed, CAS, Scopus and Google Scholar

- Research which is freely available for redistribution 